\title{
Evaluation of the energy performance of stilt houses (palafitos) of the Chiloé Island. The role of dynamic thermal simulation on heritage architecture.
}

\author{
Carla Manríquez ${ }^{1}$, Pablo Sills ${ }^{2}$ \\ ${ }^{1,2}$ Federico Santa María Technical University, Valparaíso, Chile \\ ${ }^{1}$ carla.manriquez.12@sansano.usm.cl²pablo.sills@usm.cl
}

\begin{abstract}
The stilt houses on Chiloé Island, Chile, traditionally built in local timber, are currently in poor conditions and lack of maintenance that contributes on a very poor thermal performance.To carry out interventions and inform decision making to intervene on such unique pieces of cultural heritage in fragile conditions, a computerized dynamic thermal simulation tool (software DesignBuilder $\left.{ }^{\circledR}\right)$ is used to understand and assess the energy performance of these typology of houses, identifying their annual energy losses, and determining their current annual heating demand of ten case studies. The current annual heating demand of the stilt houses is high, due to the thermal transmittance values of the building envelopes. They exceed in five times the value recommended by Chilean Building Code for the climatic zone under study. Especially critical are heat losses through the ventilated floor (external floor under DesignBuilder ${ }^{\circledR}$ template) and air infiltration, which on average contributed to $30.5 \%$ and $28.85 \%$ of all energy loss, respectively. According to simulations for ventilated floor, walls, and roofs, the obtained performance could be improved to $65 \%$ with thermal reconditioning and measures to enhance airtightness, although the feasibility of such interventions without damaging the heritage houses needs to be carefully considered.
\end{abstract}

Keywords: Vernacular Dwellings, Stilt Houses, Energy Simulation, Thermal Envelope

\section{INTRODUCTION}

The stilt houses were built from the XIX century on in Chiloé (Rojas, 2012). They were established as informal settlements located on the edge of the urban area of Castro, on the seashore, a zone administered by the Chilean Navy. Until today, they keep an informal status in regard to tenure, without regulations and documentation where this type of neigh- borhood is regularized.

Within the above situation, the thermal performance of this houses is unknown, however due to their conservation status it can be predicted that the performance is very poor and there are very inefficient. The reasons resides on the gaps on the wood floor deck, which produced an undesired airflow

There are no records of studies utilizing comput- 
erized dynamic thermal simulation tool to evaluate this type of housing. Therefore, the possibility of anticipating and suggesting rehabilitation measures for this fragile and exclusive cultural heritage gives an opportunity to research in an unexplored field. By implementing a mixed methodology that combine simulation with in situ measurements to analyze the performance of each component of the thermal envelope separately, will be crucial for the decisionmaking and technical feasibility of intervention in

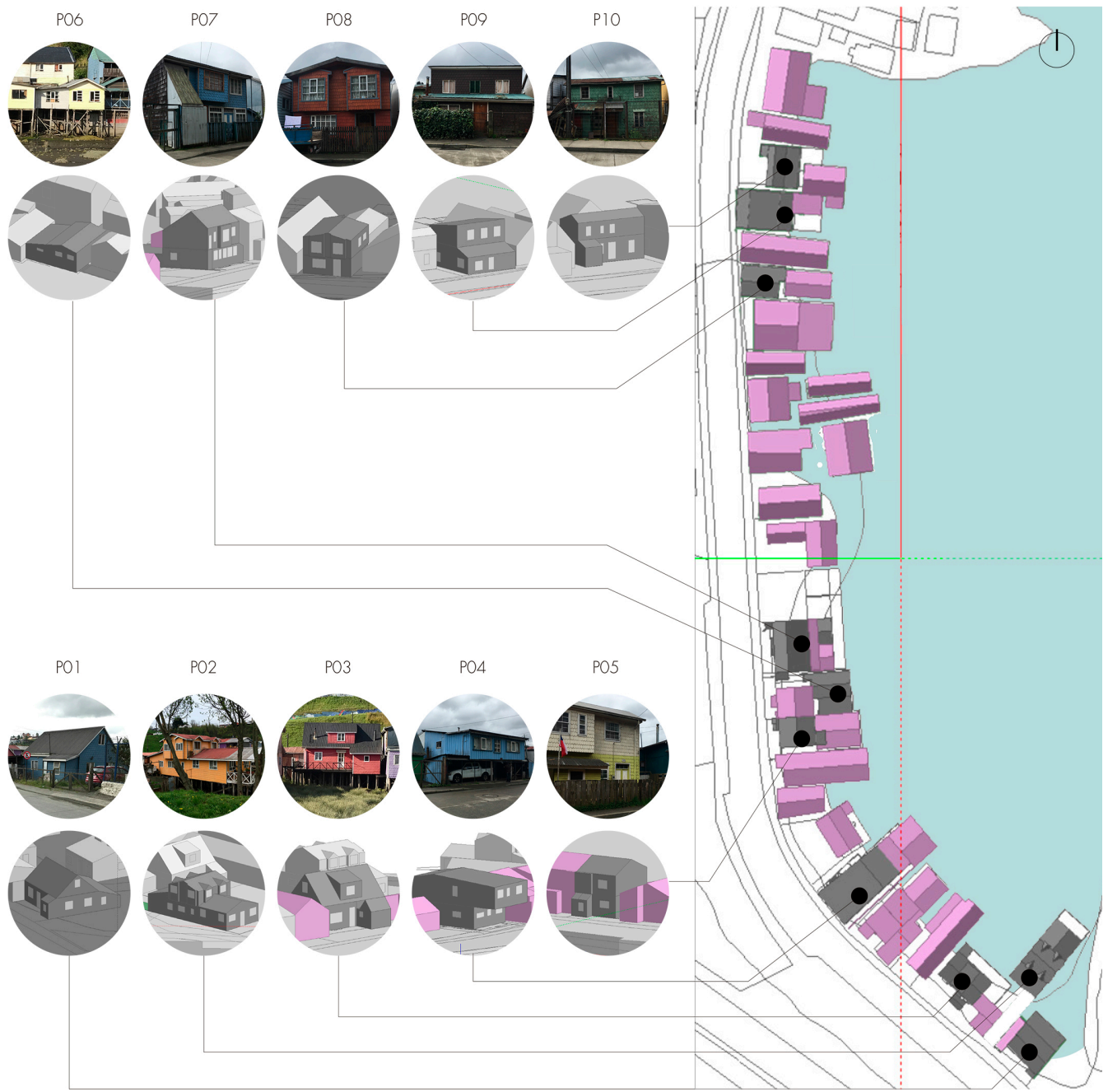

Figure 1

3D model of

DesignBuilder and photographs of stilt houses. 
Figure 2

Graphic diagrams.

Losses of energy of walls, ventilated floor, roof, windows and infiltrations of six stilt houses.
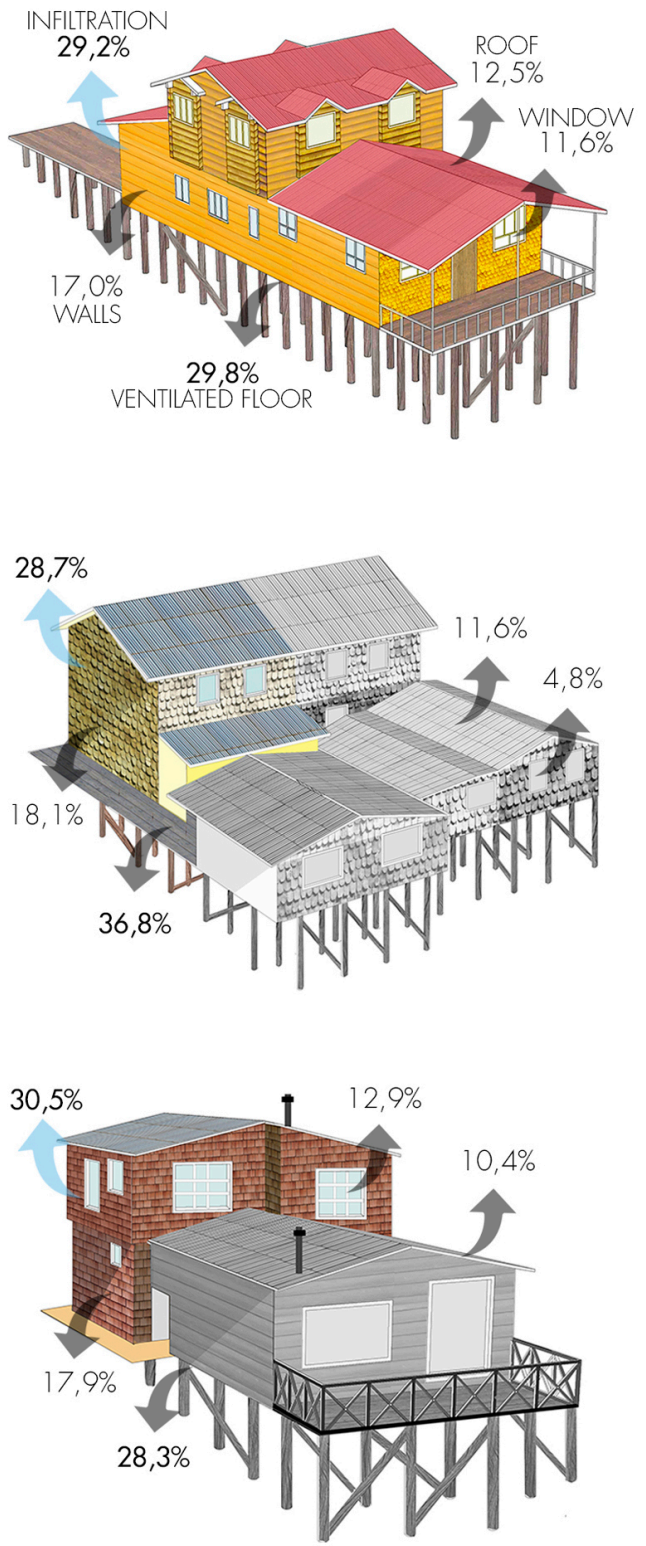
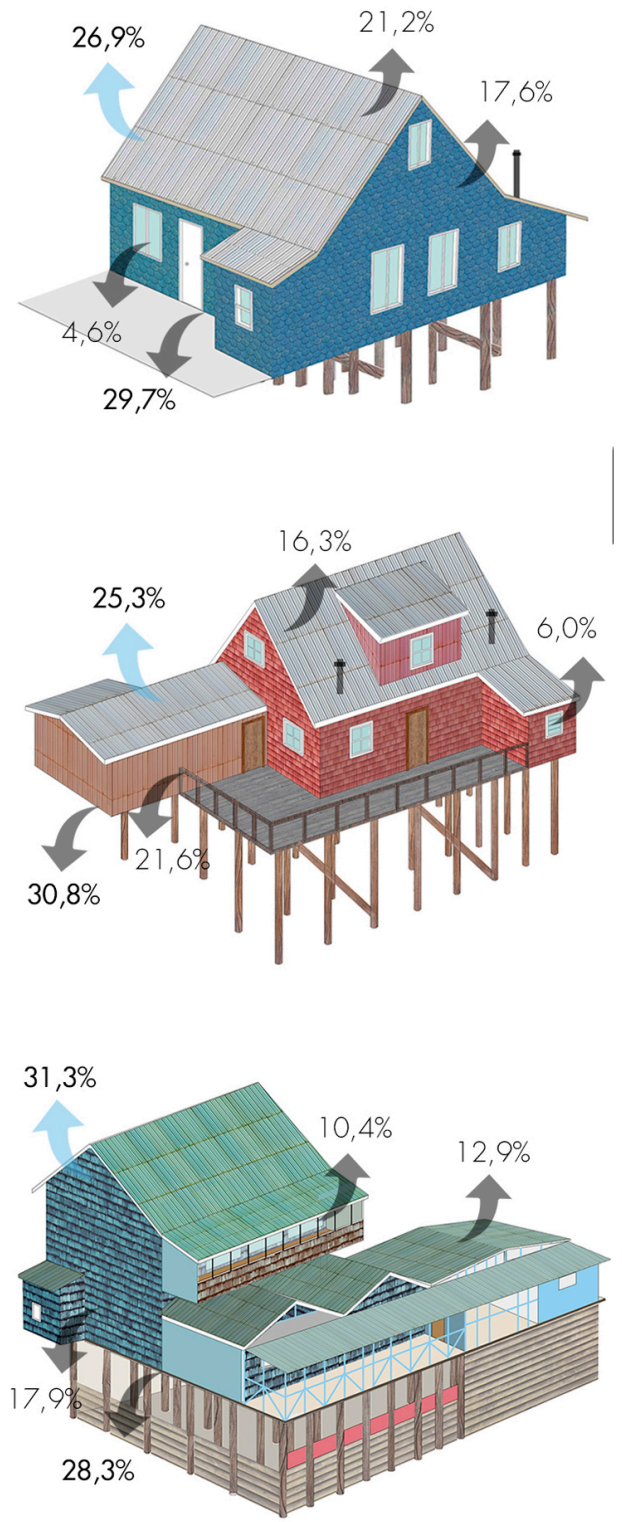
these heritage buildings, in order to preserve their value.

Furthermore, the development of this research directly involves the inhabitants of the case study and awakes an interest in them of understanding what the condition of their stilts is and which are the possibilities to improve them. Additionally, it achieves a deep comprehension of their constructive system and morphology of their homes which has architectural value.

\section{METHODOLOGY}

The proposed research involved mixed methodology that combines simulation with in situ measurements to generate and analyze qualitative and quantitative data.

Analyzing the thermal performance of the thermal envelope will first require reviewing sources containing historical information about stilt houses, the architectural and social values of the neighborhood as well as the lifestyle of the inhabitants. This study will produce both qualitative and quantitative data obtained through visits, measurements, surveys, indoor and climate instruments, and thermal infrared imaging. These tools are the basis for the simulation and evaluation of the current status of the case study.

\section{Datalogging:}

Installing dataloggers for one week in 14 randomly selected stilt houses generated data regarding the indoor temperature and relative humidity, obtaining the percentage of time during which the houses reached $20^{\circ} \mathrm{C}$ while being in-use by its occupants, determining in this way a representative week, which data will provide the numbers needed to calibrate the energy simulations model.

\section{Survey:}

Out of 32 stilt houses, to represent the historical, architectural, morphological, and construction typology ten were selected. They were 3D modeled in the software DesignBuilder ${ }^{\circledR}$ version 5 -0.3.007 and EnergyPlus version $\mathbf{8 . 5}$. (figure 1 )
The DesignBuilder ${ }^{\circledR}$ model (figure 1) includes climate, orientation, room's zones, activities, HVAC, and different building materials used in the envelope, including walls, ventilated floor, ceilings, and openings of each stilt house, as well as the current air infiltration level in air changes per hour (ACH). A diagnosis of the current thermal transmittance of walls, floors and ceilings, heat energy loss, and annual heating demands also be performed.

Calibrating the model require analyzing the free running temperatures and infiltration rates of the houses during occupancy. Free running temperatures obtained by using DesignBuilder ${ }^{\circledast}$ are compared with values obtained from the dataloggers, whereas the infiltration rates will require further investigation to elucidate how many $\mathrm{ACH}$ are used in the air infiltration specific typology.

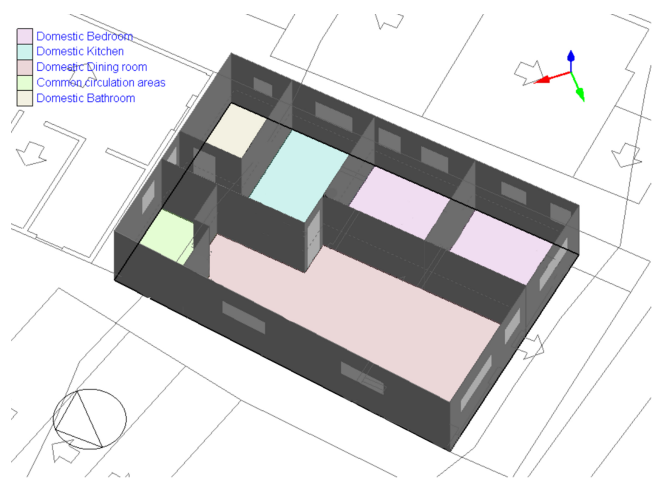

Given their poor condition, the air infiltration level in the homes is critical. At the same time, since the number of ACHs applied generate wide variety of values for heating demands, the number of $\mathrm{ACH}$ needs to be specified as accurate as possible.

DesignBuilder ${ }^{\circledast}$ allows defining whether the material envelope of the houses is "very poor", "poor", "medium", "good", or "excellent" in terms of airtightness based on predetermined templates.

Considering the poor condition of the houses, all samples will be catalogued as very poor, with $\mathrm{ACH}$ fluctuating between 2.5 and 3.0 (n4) for each type.
Figure 3

DesignBuilder's templates as "residential spaces" 
Minimum values to use as a reference since wooden houses in Chile have an average of $24.6 \mathrm{ACH}(\mathrm{n} 50)$ (CITEC UBB and DECON UC, 2014).

The thermal insulation and airtightness are improved for each component, the ventilated floor, walls and roof, through the DesignBuilder ${ }^{\circledast}$ simula- $^{-}$ tion. This generates a "poor", "medium", "good", or "excellent" building material envelope. But, to that end, $1 \mathrm{ACH}$ is the maximum air infiltration level to use into the improved envelope, because DesignBuilder ${ }^{\circledR}$ interprets "good" and "excellent" values up to 0.2 $\mathrm{ACH}(\mathrm{n} 4)$, which are very low values for the Chilean standard, especially for social and low-income house thermal retrofitting.

Rooms, activities, HVAC, and materials of the building envelope.. The rooms of stilt houses are interpreted considering DesignBuilder's templates as "residential spaces" (figure 3), since the houses are not subject to any other large-scale commercial or tourist uses. The templates also indicate the activity level of the occupants, which has tended to be passive and static due to the cold, rainy climate in which occupants have historically gathered around heat sources located in the kitchen or dining room, if not both.

In the Chilean region studied, traditions such as the using wood for heating and the prolonged proximity of inhabitants next to heat sources require making certain adjustments to the templates of DesignBuilder ${ }^{\circledast}$ regarding, for example, the number of occupants, the time that they remain in the stilt houses on a daily basis, and their prolonged use of the kitchens and living rooms.

For HVAC in the stilt houses, wood stoves and slow combustion heaters are commonly used. The most efficient wood-fired heaters are exhibited between $65 \%$ and $70 \%$ efficiency, whereas wood heaters and wood-burning stoves exhibited 35\% efficiency, and fireplace were the least efficient, about 25\% efficiency (MINVU, 2018). Therefore, 35\% efficiency was used in energy simulations.

Once the houses were surveyed, it was possible to determine materials used in their structures and building envelope. The greatest difference between housing typologies on the Chiloé Island is the exterior cladding of stilt houses using mostly tiles of larch wood, fiber cement and corrugated metal sheets. Most of the wood cladding came from local native forest.

Piles and structures ranging from beams to trusses have always been wooden in the stilt houses, given the heritage value of the construction system typical of the Chiloé Island. Originally constructed with native woods such as Luma, Canelo, Coigüe, and Tenio, the houses' interior cladding and structures have been made primarily of pine since the 1970s.

From the templates in DesignBuilder ${ }^{\circledast}$, it is possible to determine the thermal transmittance values of each building envelope component according to their construction layers and in consideration of their thermal conductivity, density and thickness.

Based on those factors, the current thermal transmittance of the walls, ventilated floors, and roofs, as well as the energy loss and annual heating demand were obtained, which later allowed to specify new values for improved building envelopes at different levels.

\section{Simulation:}

Counting on the current thermal performance of stilt houses and its walls, ventilated floor and roof helps to visualize improvements in the thermal envelope and highlight the energy loss and the reduction of the annual heating demand. (figure 2)

Energy simulation are made using as a reference the most demanding $U$ values for ventilated floor, walls, ceilings and openings included in the thermal standards of Chilean Building Codes, O.G.U.C. (2007), NCh 1079 (2008) and NTM11 (2014) (Bustamante, 2012)

S1: Ventilated floor with thermal insulation and airtightness improvements ( $\mathbf{U}$ value $=\mathbf{0 , 3 9} \mathbf{W} / \mathbf{m}^{\mathbf{2}} \mathbf{k}$ )

S2: Walls with thermal insulation and airtightness improvements ( $\mathbf{U}$ value $=\mathbf{0 , 4 0} \mathbf{W} / \mathbf{m}^{\mathbf{2}} \mathbf{k}$ )

S3: Roof with thermal insulation and airtightness improvements $\left(\mathbf{U}\right.$ value $=\mathbf{0 , 2 5} \mathbf{W} / \mathbf{m}^{\mathbf{2}} \mathbf{k}$ ) 

S4: (S1 + S2)
S5: $(\mathbf{S 1}+\mathbf{S 2}+\mathrm{S} 3)$

\section{Results display:}

The graphic diagrams are to show occupants about the current condition of their homes, with the purpose of involving and informing them about the benefits of rehabilitating their homes. (figure 2)

\section{RESULTS \\ CURRENT STATUS}

The ten stilt houses case study built with wooden partitions without thermal insulation, showed high levels of infiltration, and the thermal transmittance parameters of the single-pane glass windows are far from complying with the Chilean regulations. On average, the transmittance values are $2-3 \mathrm{~W} / \mathrm{m}^{2} \mathrm{~K}$, whereas the regulations required values are $0.25-0.4$ $\mathrm{W} / \mathrm{m}^{2} \mathrm{~K}$. (Bustamante, 2012)

On average, about $28.85 \%$ of the annual heat loss has been due to air infiltration, at a rate of 2.5 -
3.0 ACH per each stilt house. For the ventilated floors the energy loss has an average of $30.25 \%$, due to the poor building materials conditions and their badly built construction using traditional techniques. Such results are evidenced through thermal infrared imaging taken underneath the kitchens rooms (figure 6), which are the traditionally heated areas (Sahady, 2014). Meanwhile, an average of nearly $18.02 \%$ of heat is lost through walls, $15.32 \%$ through roofs and $7.54 \%$ through openings (doors and windows), the latest is due to the small dimensions compared to the wall's areas. (figure 2,4 )

According to the compactness, materiality, unit's distribution, and level of infiltration in each stilt house, the annual heating demand is $235.53 \mathrm{kWh} / \mathrm{m}^{2}$ on overage. However, according to the sustainable construction standards for homes in Chile in the climatic zone in question, the annual heating demand in 2020 should be no more than $120 \mathrm{kWh} / \mathrm{m}^{2}$. (MINVU, 2018)

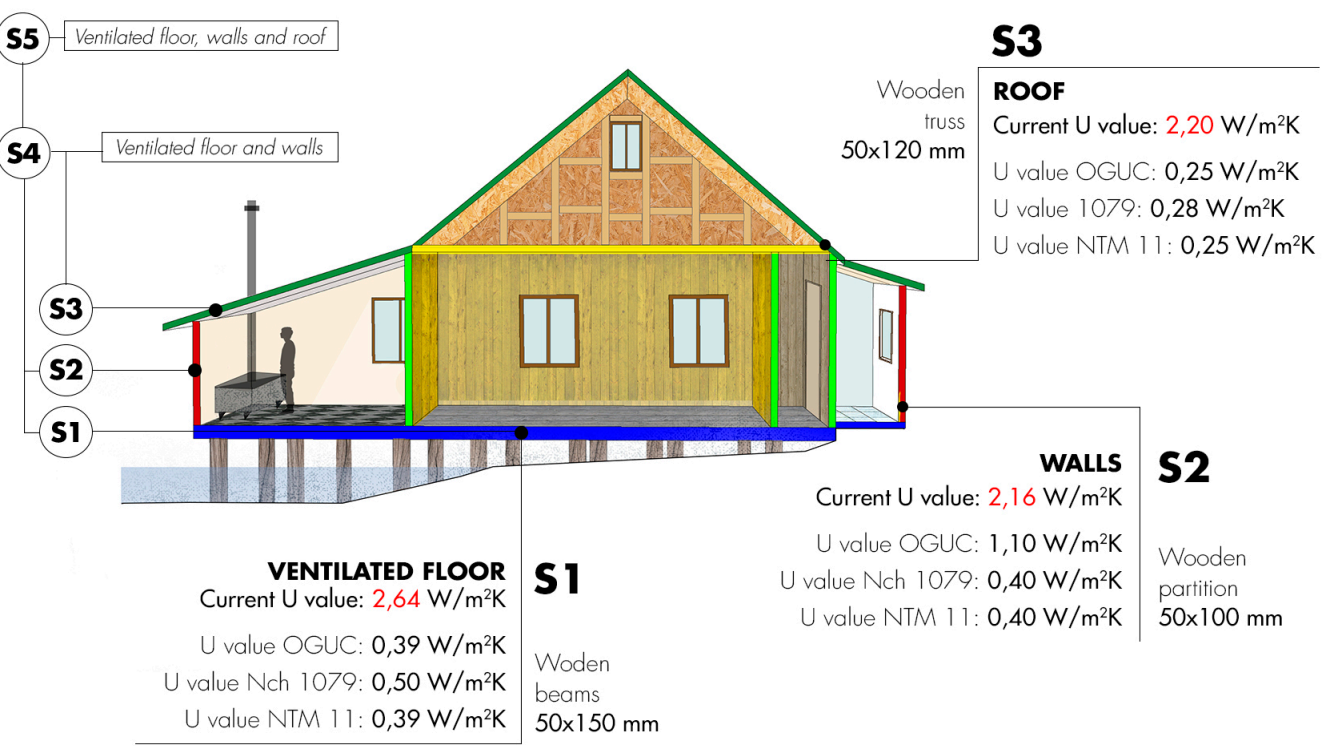

Figure 4

Stilt house' section with current thermal transmittances and reference U-values. 
Figure 5

Reduction in annual heating demand.

Figure 6

Thermal infrared imaging taken underneath the kitchens rooms.

\begin{tabular}{|c|c|c|c|c|c|c|c|c|c|c|}
\hline & \multicolumn{10}{|c|}{ Stilt House } \\
\hline & P01 & P02 & P03 & P04 & P05 & P06 & P07 & P08 & P09 & P10 \\
\hline S1 & 36,13 & 39,37 & 45,05 & 44,57 & 41,92 & 45,42 & 43,33 & 48,60 & 55,95 & 53,78 \\
\hline S2 & 20,22 & 34,47 & 31,93 & 35,92 & 30,85 & 23,98 & 34,64 & 38,43 & 39,11 & 37,65 \\
\hline s3 & 13,58 & 28,89 & 19,55 & 29,52 & 25,64 & 28,05 & 28,40 & 36,80 & 30,72 & 27,75 \\
\hline S4 & 52,68 & 56,11 & 66,35 & 68,64 & 59,93 & 64,03 & 65,85 & 66,98 & 60,81 & 64,03 \\
\hline S5 & 59,89 & 67,66 & 76,61 & 74,54 & 72,79 & 75,40 & 76,20 & 74,23 & 75,00 & 76,40 \\
\hline
\end{tabular}

13,58

76,61

\section{ENERGY SIMULATION RESULTS:}

Reconditioning ventilated floors (S1) in the stilt houses could reduce energy losses by $\mathbf{3 8 . 9 4 \%}$ on average and up to $\mathbf{4 5 , 4 1 \%}$ of the annual heating demand. Reconditioning the walls (S2) and ceilings (S3) of the houses separately, by contrast, would allow a lower reduction of energy loss and fewer savings in annual heating demand. Reconditioning the walls would reduce the loss by about $\mathbf{2 5 . 2} \%$ and annual heating demand by an average of $\mathbf{3 2 , 7 2 \%}$; reconditioning the ceiling would allow $\mathbf{2 4 . 7 4 \%}$ less energy loss and, on average, a reduction of $\mathbf{2 4 , 0 8 \%}$ in annual heating demand.
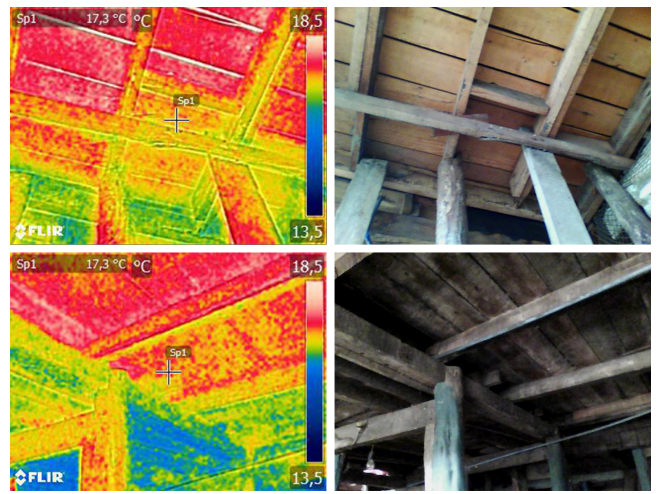

In all three cases, the simulations performed revealed that enhancing the airtightness of the building envelope could allow an average decrease of $40 \%$ in $\mathrm{ACH}$ for each stilt house.

By reconditioning ventilated floors and walls (S4), the reduction of energy loss would be up to $54 \%$ and in annual heating demand by up to $62,54 \%$, with an average reduction of $1.3 \mathrm{ACH}(\mathrm{n} 4)$.

Last, reconditioning the three building component, walls, ventilated floors, and ceilings (S5) would allow up to $65 \%$ less energy loss, considering the limit of $1 \mathrm{ACH}(\mathrm{n} 4)$. As for annual heating demand, up to $66,98 \%$ of the current demands, or $70 \mathrm{kWh} / \mathrm{m}^{2}$ on average, could be lowered. (figure 2, 5)

Relationship of the results with the construction and economic reality of the houses.. In terms of construction, four of the 10 stilt houses had wooden partitions of $50 \times 100 \mathrm{~mm}$, whereas the others had partitions of $50 \times 75 \mathrm{~mm}$.

In terms of ventilated floors, two stilt houses from the 1920s have larger beams, which allowed them to withstand the impact of the 1960 earthquake. Those houses have $75 \times 200 \mathrm{~mm}$ wooden beams, whereas the homes built after the earthquake have ones of $50 \times 150 \mathrm{~mm}$, as well as wood flooring finished without any insulation. Also, the ceiling in the two oldest houses have wooden trusses of $50 \times 150 \mathrm{~mm}$, whereas the others have ones of $50 \times 120$ $\mathrm{mm}$. 
Identifying the thickness of the facings made it possible to propose the benefits of thermal reconditioning and which material used in their construction would be most pertinent from a technical point of view. For example, mineral wool is the most widely available insulating material on the market for the inhabitants; with a density of $11 \mathrm{~kg} / \mathrm{m}^{3}$ for a wooden partition of $50 \times 100 \mathrm{~mm}$, mineral wool can meet the $U$ value of thermal transmittance during simulated occupancy, although not for a partition of $50 \times 75 \mathrm{~mm}$, unless it has a higher density, which would make the thermal reconditioning more expensive. Consequently, ventilated floors and ceilings, depending on their dimensions, could benefit from thermal reconditioning with mineral wool, as supported by previous energy simulations.

A way to meet the requirements of Building code would be to use projected polyurethane due to its low thermal conductivity. Such an alternative could be feasible specifically for ventilated floors as an option to quickly seal that part of the stilt houses. Moreover, such reconditioning would not compromise the heritage value of the construction technique of that element.

By contrast, increasing the size of the structure or adding layers to the facings could be another option. Despite it invasiveness and expense, it can be used in deficient conservation conditions in which structures are damaged, thereby allowing a total rehabilitation of the affected facings without compromising the patrimonial value.

Because each stilt house presents unique construction and morphological qualities, the solutions projected by the simulations often conflict with the economic reality and physical limitations in realizing what the simulations project, especially without jeopardizing the heritage-related value of the houses, which is intrinsic in their kind of housing typology. For example, the narrow space between one house and another makes it impossible for people to gain the access needed to replace elements of the enclosure. (figure 7)

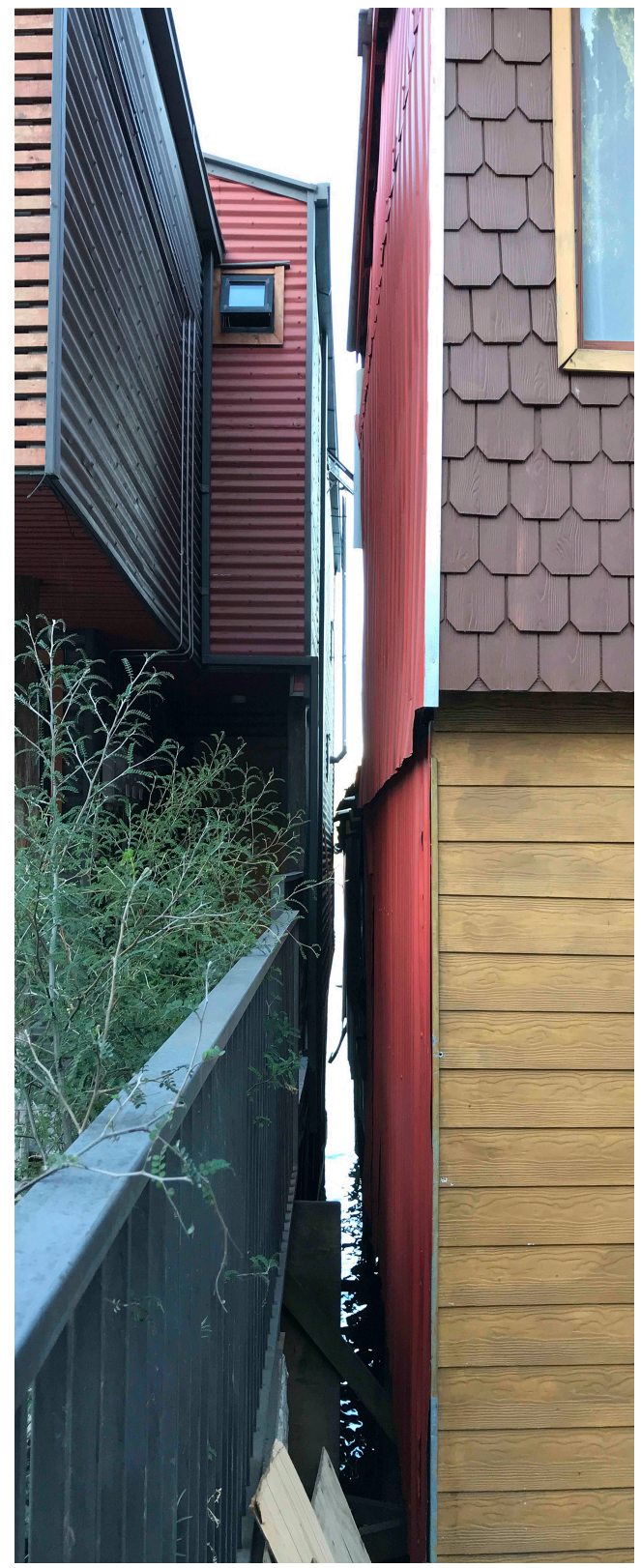

Figure 7

Narrow space between stilt houses. 


\section{DISCUSSION}

The results of the energy simulation for each component of the building envelope clarified each component's energy performance. Such information is pivotal to.

Determining the feasibility of improving the traditional techniques used to construct the houses without jeopardizing their heritage value, as well as to identifying which interventions are most appropriate to maintain such value while improving their thermal performance.

Anticipating energy-use scenarios in the stilt houses allows visualizing the current state of their thermal performance in real values, which can inform ways to intervene sustainably in places where the greatest benefits can be obtained. In that sense, thermal reconditioning has the greatest potential to reduce air pollution, as well as can drastically decrease heating needs, energy expenditure, and energy poverty levels (Schueftan et al, 2016).

When each component of the thermal envelope is studied separately, results regarding energy performance can be acquired by successive iterations of simulations of such performance in relation to energy demands.

In that case, sustainability can be achieved first by making cost savings in heating demand visible, which is critical in areas with higher demands regarding heating (Vera, Ordenes, 2002). In particular, achieving social, environmental, and economic sustainability in the houses requires rehabilitating their thermal envelopes so that they consume less heating and reduce air pollution, all while maintaining the cultural identity of the inhabitants as part of the process of maintaining the heritage value of their houses.

In calibrating the model in DesignBuilder, the
$\mathrm{ACH}$ is a fundamental value for pinpointing heating demand as "a substantial factor that must be specially revised to develop reliable studies" (GarcíaÁlvarado et al., 2014) involving, for example, onsite visits (blower door test).

At the same time, due to the region's cold, wet, rainy weather, typical inhabitants in the region prepare food, heat their houses, and dry clothes with traditional stoves fueled with firewood. Although such processes produce excess vapor and internal heat, those circumstances have not affected the interior walls due to high levels of air infiltration. Presumably, interventions in the building envelope may affect those day-to-day behaviors and, in turn, undermine traditions in the long term.

\section{Feasibility of rehabilitation:}

Due to the informal emplacement of the stilt houses, the lack of documentation regarding them, and the economic struggles of their inhabitants, rehabilitating the building envelopes of the stilts houses continues to present a dilemma. In response, it is urgent for institutions to recognize the neighborhoods as cultural heritage sites and to provide economic support for the rehabilitation of the houses therein. Such efforts should halt the accelerated material deterioration of the houses and reduce the risk of the disappearance of a housing typology that represents a key component of the archipelago's history.

From a technical standpoint, however, it is impossible to intervene into the entire building envelope of the stilt houses due to the informal grouping system, while from an economic one, no financing programs for such rehabilitation currently exist. By contrast, from the standpoint of cultural heritage, the interventions need to ensure the maintenance of the heritage value of the traditional ways of building stilt houses.
Figure 8

photography of the neighborhood of stilt houses (case study).

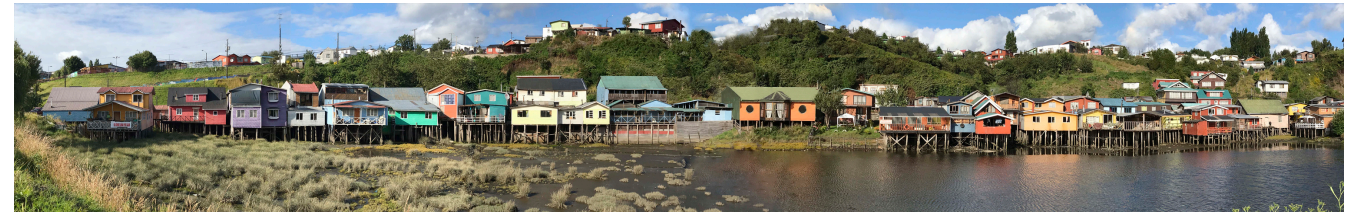


Last, the heritage value of the stilt houses demands the in-depth study of their architectonical, historical, and social value, in addition to the conditions for their conservation. The energy simulations and evaluations of the buildings allow detailed results regarding economic performance that can inform strategic interventions for their rehabilitation that are at once technically and economically feasible. No matter whether such interventions are minor or major, they must maintain and respect the heritage values of the houses while extending their lifespans.

\section{REFERENCES}

Bustamante, W. 2009, Guía de Diseño para la Eficiencia Energética en la Vivienda Social, Pontificia Universidad Católica de Chile, Santiago de Chile

Citec, UBB and Decon, UC 2014, Manual de Hermeticidad al aire de Edificaciones, Universidad del Bío-Bío, Concepción, Chile

MINVU, Ministerio de Vivienda y Urbanismo 2013, Guía de recomendaciones para la reparación y puesta en valor de los palafitos de Castro, Departamento de Desarrollo Urbano e Infraestructura, Secretaría Regional Ministerial de Vivienda y Urbanismo, Castro, Chile

Rojas, E. 2012, Palafitos de Castro/Chiloé: patrimonio vernacular, Chilean Academy of history, Santiago de Chile

Sahady, A., Bravo, M., Quilodrán, C. and Gallardo, G. 2011 , 'La cocina chilota: el genuino lugar de encuentro de una comunidad bordemarina', INVI, 24(67), pp. 155172

Schueftan, A., Sommerhoff, J. and González, A. 2016, 'Demanda de leña y políticas de energía en el centro-sur de Chile.', Boletín BES, Bosques - Energía - Sociedad, 5, pp. 1-19

Vera, S. and Ordenes, M. 2002, 'Evaluación del desempeño energi-térmico de una vivienda social en chile, utilizando un programa de simulación energética de edificios.', Revista Ingeniería de Construcción, 17(1), pp. 133-142

[1] http://www.calificacionenergetica.cl 